TP Periodica Polytechnica Civil Engineering

61(1), pp. 56-65, 2017

DOI: 10.3311/PPci.9521

Creative Commons Attribution (i)

RESEARCH ARTICLE

\section{Optimization of Tunnel Boring Machine (TBM) Disc Cutter Spacing in Jointed Hard Rock Using a Distinct Element Numerical Simulation}

\author{
Masoud Zare Naghadehi ${ }^{*}$, Reza Mikaeil ${ }^{2}$
}

Received 23-05-2016; accepted 03-07-2016

\begin{abstract}
The Tunnel Boring Machine (TBM) tunneling process in hard rock is actually breakage of a rock mass that is not necessarily intact. Thus, undoubtedly, joints and discontinuities play a role in TBM performance. In addition, this performance depends on the rock breakage efficiency induced by the TBM cutterhead. Both the rock mass and the TBM specifications affect the rock breakage and chipping process and thus in the machine efficiency. In this paper, the chipping process in a type of jointed hard rock under indentation by two TBM disc cutters has been numerically simulated using the Discrete Element Method (DEM) in two dimensions. The spacing of the cutters has been optimized regarding optimization of some defined criteria such as chip thickness, chipping area and also significantly the penetration rate. The optimum cutter spacings on the selected hard and jointed rock were identified to be in the range about 110 to $140 \mathrm{~mm}$ for different joints frequencies. According to the simulation results, it is believed that the numerical simulation will contribute to an improved knowledge of rock fragmentation, which will in turn help to enhance mining, drilling and tunneling efficiency through the improved design of mining tools and equipment.
\end{abstract}

\section{Keywords}

Tunnel Boring Machine, disc cutter, optimization, jointed hard rock, numerical simulation

\footnotetext{
${ }^{1}$ Department of Mining Engineering, Hamedan University of Technology (HUT), Hamedan, Iran

${ }^{2}$ Department of Mining and Metallurgical Engineering, Urmia University of Technology, Urmia, Iran

${ }^{*}$ Corresponding author, e-mail: masoud.zare@hotmail.com
}

\section{Introduction}

Rock cutting with a Tunnel Boring Machine (TBM) involves the indentation of a rock surface by cutting tools, which are mounted in an array on the front of a cutterhead. A simplistic view of a TBM would be that of a machine which generates thrust to push the cutterhead forward and supplies torque to turn the cutterhead against the tangential forces resisting the cutting tool motion and indentation [1]. During the excavation, TBM disc cutters roll across the tunnel face and continuously expand the crushed zone immediately beneath them. Then, cracks are initiated from the crushed zone and propagated downwards and sideward. One or more cracks under the action of the rolling cutter may reach the free surface or propagate to meet the cracks of the neighboring cuts. In these two cases, chipping occurs [2]. This interaction and subsequent fragmentation process are directly relevant to the design of the TBM cutterhead and the efficiency of TBM excavation. The line spacing of adjacent cutters is the main parameter governing the interaction mechanism. In addition, the presence of joints and discontinuities in rock will make the interaction more complex.

This research studies the fragmentation of rock under the effect of two neighboring cutters in different joint frequencies. Most of the main former researches on various cases related to TBM disc cutters fragmentation process have been done with consideration of homogeneous and isotropic rocks. Among these investigations, those that were concerned with cutter spacing optimization and related issues are explained below.

Roxborough [3] deduced an equation for the cutter spacing, in terms of the assumption of rock shear failure between two adjacent cuts. The ratio of cutter spacing to penetration is equal to the ratio of the uniaxial compressive strength to the shear strength. By utilizing the linear rock cutting rig, Snowdon et al. $[4,5]$ performed a series of linear cutting tests. The effects of the penetration and the ratio of cutter spacing to penetration on specific energy were analyzed. The correlation between cutter spacing and the three forces acting on the cutters was also studied. The optimum value of the ratio of cutter spacing to penetration for granite, dolerite and sandstone was found to be about 10 and that for limestone was approximately 15 . The 
optimum penetration was about $10 \mathrm{~mm}$ for granite, dolerite and sandstone. Cook et al. [6] examined the effects of indenter size and confining stress on the rock indentation test and compared it with numerical simulation based on the Finite Element Method (FEM).

Rostami and Ozdemir [7] postulated that there are three different chipping patterns in terms of specific spacings, and also there is an optimal rock-cutting spacing corresponding to an effective rock-cutting condition. Based on a rock failure process analysis model, Liu et al. [8] presented a numerical code $\mathrm{R}-\mathrm{T} 2 \mathrm{D}$ to reproduce the progressive process of rock fragmentation by indenters. The failure process of the rock and the realistic crack pattern under multiple indenters in continuum rock media were observed. Gong et al. [2, 9] performed single numerical simulations to investigate joint spacing and orientation effects using the DEM based on the fixed boundary condition and load-controlled indenters. They also conducted a numerical modeling for finding single optimal cutter spacing with consideration of the properties of typical intact and homogenous granite found in Singapore [10]. They could achieve some satisfactory results that showed good agreement with experimental outcomes. Gertcsh et al. [11] performed fullscale laboratory disc cutting tests for investigation of the effect of some properties of TBM disc cutters on performance prediction in Colorado Red Granite. One of these properties was the spacing between the cutters. They found that a certain disc cutter spacing is close to the optimum specific energy in hard, brittle, crystalline rock. Fatehi Marji et al. [12] conducted numerical modeling to study the crack propagation in rocks including the crack initiation angles and propagation paths under TBM disc cutters. Cho et al. [13] performed a three-dimensional dynamic numerical analysis based on the FEM for simulating the Linear Cutting Machine (LCM) test under non-reflective boundary conditions with sequential multi-cutting paths to represent more realistic boundary conditions and the process of the LCM test. For illustrating crack and chipping formation on the modeling, a numerical elimination technique triggered by pre-determined tensile strength was employed. Moon and Oh [14] carried out a multi-indentation simulation using DEM analysis to study the optimal rock-cutting phenomena in terms of the interaction of the ratio of spacing to penetration $(s / p)$ with intact rock properties. The results of simulations and real LCM tests show that the effective rock-cutting condition corresponding to the minimum specific energy can be estimated by an optimized s/p ratio. Huo et al. [15] investigated the optimal disc cutters plane layout design of TBM by an Ant Colony Optimization (ACO) algorithm. They showed that this method improves the computational accuracy of the solutions. Sun et al. [16] also adopted a numerical simulation method based on the FEM theory to simulate the rock chipping process induced by TBM disc cutters to determine the optimal cutter spacing. A cooperative co-evolutionary genetic algorithm (CCGA) was also adopted by them to solve the disc cutters plane layout design problem. Xia et al. [17] built a mechanical model to investigate the force characteristic of TBM disc cutter and installation radius between adjacent disc cutters. Wang et al. [18] used numerical algorithms to simulate the mass and cutting forces in the boring, and finally found out the balance points in real boring in different cutting parameters. They also found out that the best cutters spacing is $76 \mathrm{~mm}$ for 17 inch cutter ring in their study. Most recently, Lu et al. [19] utilized ABAQUS software to simulate the work of two adjacent disc cutters and the rock breakage process beneath them. They also combined this computer simulation with experimental effort to optimize disc cutters spacing by which achieved optimal values of around 80-90 $\mathrm{mm}$ for their specific tested conditions.

As can be seen, numerous studies have been conducted on the fragmentation of rock under disc cutters and the optimization of cutters spacing using different numerical, analytical and experimental methods, but none of them have paid attention to the optimal spacing of the cutters in different joints spacings for hard rock TBM. Therefore, as an original research, the current study presents an attempt to simulate the cutting process of a rock mass by two adjacent disc cutters in a hard and jointed rock environment with different joint spacings using a 2D DEM code [20], the Universal Distinct Element Code (UDEC) [21]. Principally, the aim of this paper is to find the optimal spacing between two neighboring disc cutters in terms of considered joint frequencies. In this study, the models were set up based on the properties of a type of quartzite rock (both intact rock and joints properties) found in the Ghomrood tunneling project area in Iran. This type of rock was selected because it represents the hard and simultaneously jointed rock commonly encountered in field operations.

The rest of this paper is organized as follows. In the second section, a brief background is presented on the fracture mechanism of adjacent disc cutters. In the third section, the developed model's configuration and settings are explained. This part also includes the properties of material considered in this study. Then, after explanation of the fracture and chipping process, subsequent considerations and analyses are done and finally the optimal spacings are proposed for each condition. Eventually, in the last section, results of the application are reviewed.

\section{Background of the study}

During the time that a TBM is excavating the face of a tunnel, an interaction process between each couple of disc cutters is generated. The study of this process can help to design and implement of machines in appropriate geological formations.

When one or more cracks from neighboring cuts meet or cracks reach the free surface, chipping occurs. The length of the cracks is a function of the pressure in the crushed zone, which in turn is a function of the cutter normal force. The cut interaction depends on spacing between the cuts, the angle, and extension of cracks between the adjacent cuts [6]. 
Some key points are noticeable and thus are explained in this section. According to fracture mechanics principles, a crack may propagate in any direction which provides the least surface energy and until the stress intensity is over the critical stress intensity factor of the rock. This propagation can continue until stress intensity drops below the critical value or the crack meets a free surface (that can be another surface). This means that chips can be formed by cracks in any angle. Thus, the occurrence of ridge formation and overbreak of rock under different cutter loads can be explained. In the case of ridges, cracks are developed toward the cutting face and reach a free surface and form small triangular chips. This will cause a drop in the pressure of the crushed zone and prevents further propagation of cracks toward other cuts and leaves the material between the cuts almost untouched (Fig. 1(a)). The process may continue until in subsequent passes with higher cutter loads two of the cracks can interact and form a chip. If the applied load is too high, longer cracks can develop inward and meet in an angle, meaning an overbreak (Fig. 2(b)). This produces thicker chips below cutting level. For an optimum spacing, cracks are ideally propagated towards the neighboring cuts through a straight line which would be the shortest distance for crack propagation and is equal to half the spacing (Fig. 3(c)). For modeling purposes, the later case is considered to prevail while cutting with disc cutters [7].

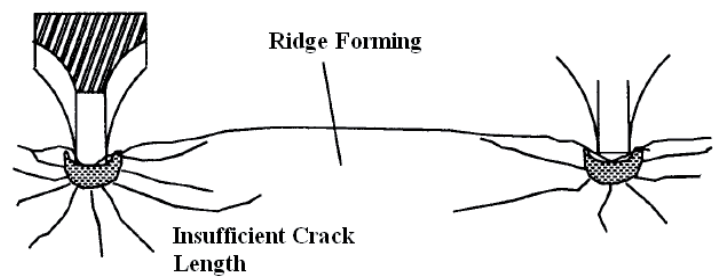

(a) Ridge formation due to lack of pressure and length of cracks

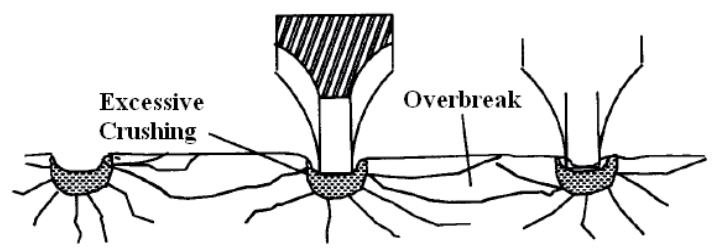

(b) Over break due to excessive loading and longer cracks

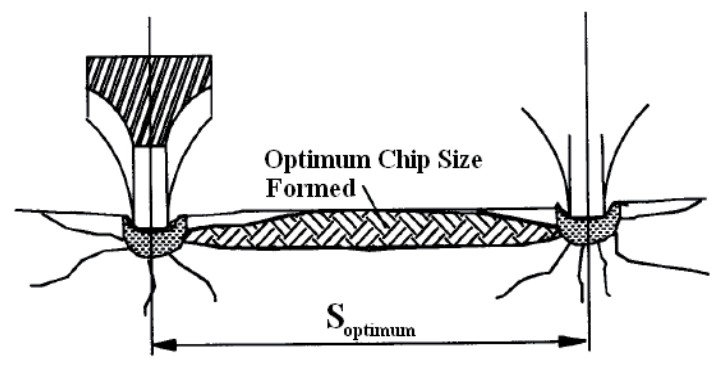

(c) Normal cutting with optimum crack length and direction

Fig. 1 Chip formation in different situations [7]
The theory explained above is just for homogenous rock media. The presence of primary fractures and joints in the medium can alter the mode of crack propagation and also the optimum spacing between two adjacent cutters. This paper surveys the interaction process in a jointed rock environment with regard to different joint frequencies using 2D numerical simulation.

\section{Model setting}

The developed computational model is schematically shown in Fig. 2. The size of the model is $1 \mathrm{~m} \times 1 \mathrm{~m}$ and one set of vertical joints is included. The joint spacing varies between 50 to $500 \mathrm{~mm}$. The dip direction of the joint set is assumed to be perpendicular to the cutters loading direction (i.e. the joint dip is 90 degrees in relation to cutting face orientation). The net distance between two cutters was set from $60 \mathrm{~mm}$ to $150 \mathrm{~mm}$. The two cutters were modeled by two normal forces applied at mid height of the left boundary through a contact thickness of 15 $\mathrm{mm}$. Since it is 2D modeling, the rolling force acting on the cutters and the resulting dynamic cutting process cannot be taken into consideration and thus the cutting process is assumed as indentation. Besides, the cutters are assumed as Constant Cross Section (CCS) discs and they are also supposed to apply simultaneous loads on the rock. Most of the previous numerical studies have modeled the disc cutters loading process in this recent fashion (double cutters) neglecting the time difference between two cuts. This can be considered as a simplification in order that the modeling could be performed by UDEC.

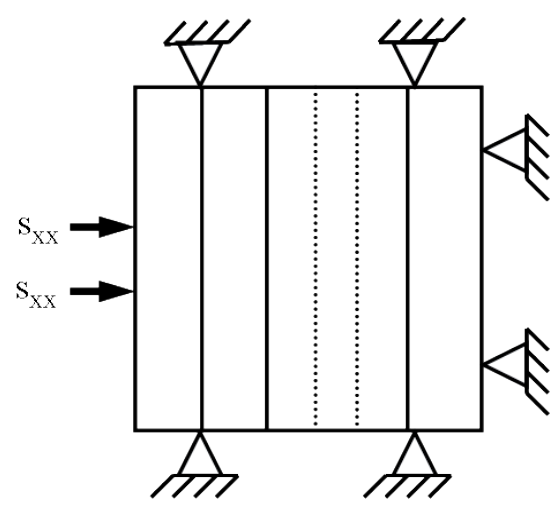

Fig. 2 The model considered for numerical simulation of chip formation between two cutters

The upper, lower and right boundaries are considered as fixed displacement boundaries. The rock blocks between the set of joints are discretized with fine element difference meshes, namely zones in UDEC. Also, the zone size was adjusted on $5 \mathrm{~mm}$ increments. In order to utilize the results in TBM designs later, the rock mass and joints properties were selected from the Ghomrood tunneling project area in Iran. The intact quartzite is regarded as an isotropic rock and assumed to be the Mohr-Coulomb material; its properties are listed in Table 1, while all joints satisfy the Coulomb slip model with the properties summarized in Table 2. 
Table 1 Properties of intact quartzite [22]

\begin{tabular}{ll}
\hline Properties & Value \\
\hline Bulk density $(\mathrm{kg} / \mathrm{m} 3)$ & 2800 \\
Bulk modulus $(\mathrm{GPa})$ & 29 \\
Shear modulus $(\mathrm{GPa})$ & 18 \\
Cohesion $(\mathrm{MPa})$ & 11 \\
Friction angle (degree) & 38 \\
Tensile strength (MPa) & 6.5 \\
Dilation angle (degree) & 10 \\
\hline
\end{tabular}

Table 2 Properties of rock joints [22]

\begin{tabular}{ll}
\hline Properties & Value \\
\hline Normal stiffness $(\mathrm{GPa} / \mathrm{m})$ & 6 \\
Shear stiffness $(\mathrm{GPa} / \mathrm{m})$ & 3 \\
Cohesion $(\mathrm{MPa})$ & 1.25 \\
Friction angle $($ degree $)$ & 21 \\
Tensile strength $(\mathrm{MPa})$ & 0.02 \\
\hline
\end{tabular}

Based on the field observations and statistical analysis of over $250 \mathrm{~km}$ of TBM excavated tunnels in hard rock conditions for more than 20 years, Bruland [23] divided the discontinuities into two sorts, namely joint and fissure, and five classes as listed in Table 3.

Table 3 Fracture classes with distance between the planes of weakness [23]

\begin{tabular}{ll}
\hline Fracture classes & Distance between planes of weakness $(\mathrm{mm})$ \\
\hline 0 & - \\
0-I & 1600 \\
I- & 800 \\
I & 400 \\
II & 200 \\
III & 100 \\
IV & 50 \\
\hline
\end{tabular}

To model different joint spacings, some of these classes of spacings were chosen with some slight changes in defining subclasses. Thus the joints spacings were divided into six classes $(500,400,300,200,100$ and $50 \mathrm{~mm})$ that mostly lay in and between the Bruland's spacing classes.

\section{Fracture and chipping process under indentation of two cutters}

The rock fracture and chipping process induced by double disc cutters are assumed. At the first stage of loading, the respective stress fields induced by the double cutters are equal to those induced by the single cutter. The rocks immediately under the indenters are highly stressed. The stresses decrease rapidly with increasing distance from the loading points. Cone cracks around the two corners of both cutters are initiated first. Before the formation of the crushed zone, the cone cracks bifurcate and propagate approximately parallel to the free surface and are expected to form side cracks. The interactions between the side cracks are more obvious as the tips of the side cracks become closer and closer. The chipped rock has a complicated geometrical shape. More cracks are initiated from the crushed zone. Some of them propagate to form side cracks and some of them dip into the rock forming subsurface cracks. At the same time, some discrete cracks are initiated under the crushed zones to form radial and median cracks. Finally, after the major chips, some small chips occur.

The presence of joints in a rock medium alters this process; however, the basics of fracture and chipping process are the same as mentioned above. Figure 3 shows the major principal stress contours in joint spacing of $200 \mathrm{~mm}$.

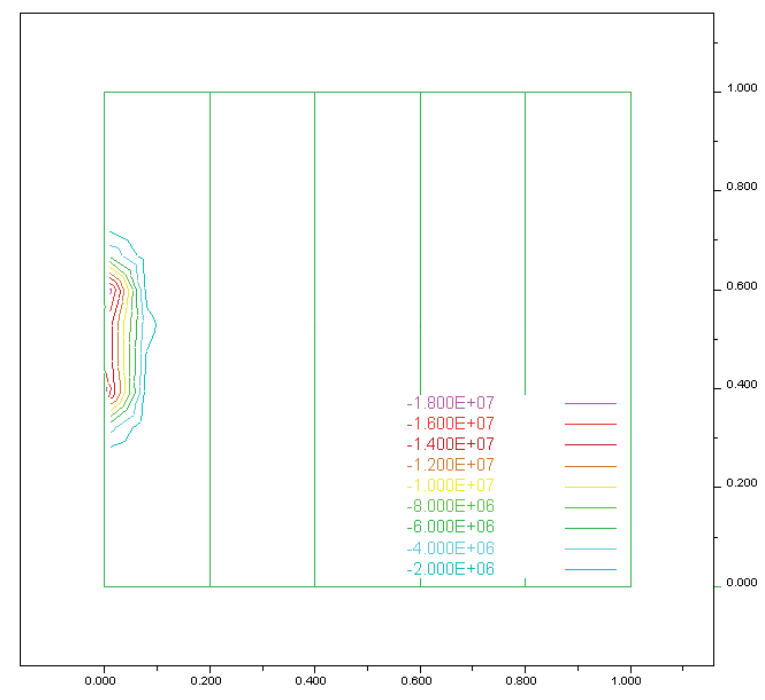

Fig. 3 Major Principal Stress contours with two cutters indentation in joint spacing of $200 \mathrm{~mm}$

As can be seen, the stress field is symmetrical and the stress is extremely high immediately beneath the cutters and decreases rapidly with increasing distance from each cutter edge. A high stress zone is formed between the two cutters. Under the action of the high stress zone, the chip between the cutters is formed due to tensile failure. When the depth beneath the cutters is more than 1 to 1.5 times the cutter spacing, the major principal contour resembles that of the single cutter indentation.

\section{Cutter spacing optimization}

The optimal states for simulated models are shown in Figures 4 -9 (in these figures green crosses denotes plastic yield and purple circles denote tensile failure). As can be seen, the shape and thickness of the rock chips are different for each optimum state. The stress acting on the cutters was recorded and the chip thickness and chipping area were measured for each joints spacing. These measurements are shown in Tables 4 to 9 (in these tables CA/CS is Chipping Area/Chipping Stress, CW/ CT is Chip Width/Chip Thickness, CA is Chipping Area, CT is Chipping Thickness, CS is Chipping Stress, CSp is Cutter Spacing, and NC is No Chip). 


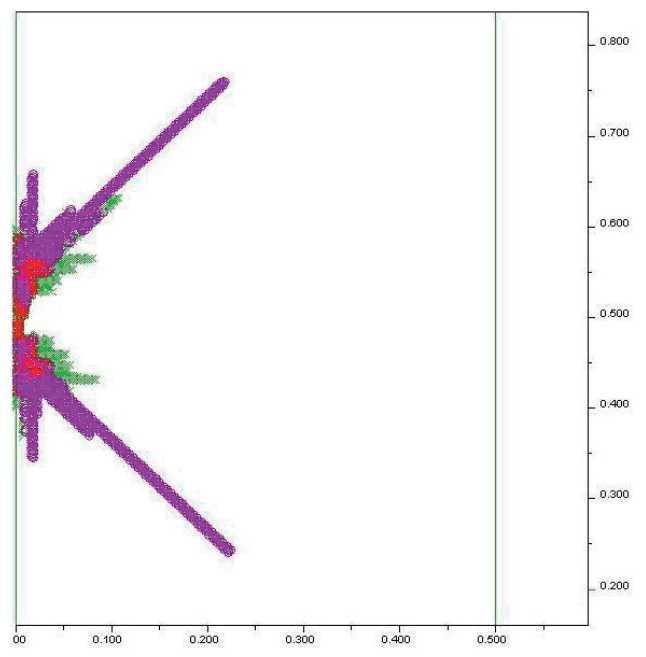

Fig. 4 Chipping formation in optimal cutter spacings joint spacing: $500 \mathrm{~mm}$ at step 1000

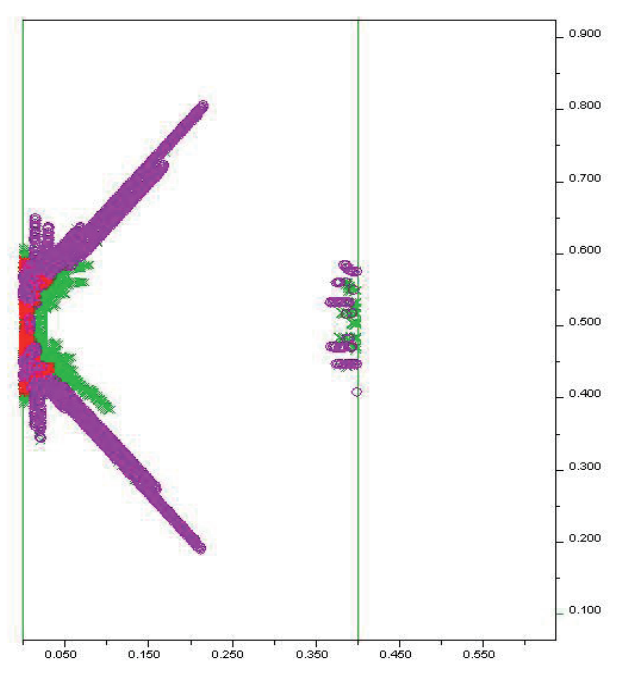

Fig. 5 Chipping formation in optimal cutter spacings joint spacing: $400 \mathrm{~mm}$ at step 1000

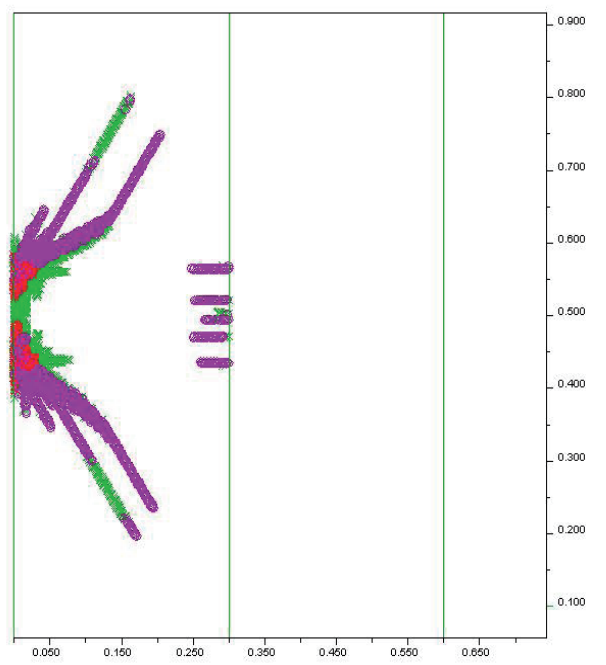

Fig. 6 Chipping formation in optimal cutter spacings joint spacing: $300 \mathrm{~mm}$ at step 1000

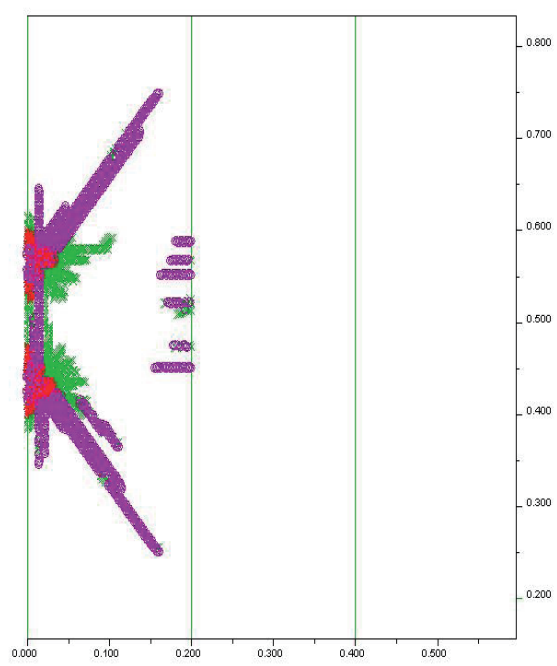

Fig. 7 Chipping formation in optimal cutter spacings joint spacing: $200 \mathrm{~mm}$ at step 1000

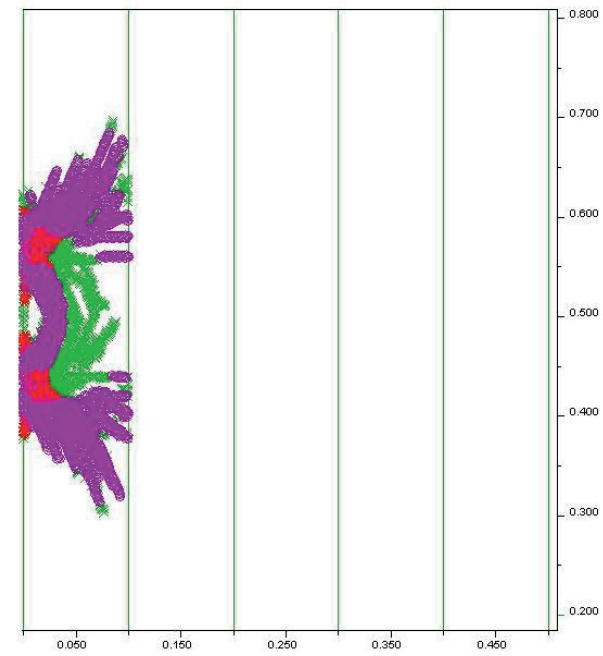

Fig. 8 Chipping formation in optimal cutter spacings joint spacing: $100 \mathrm{~mm}$ at step 1000

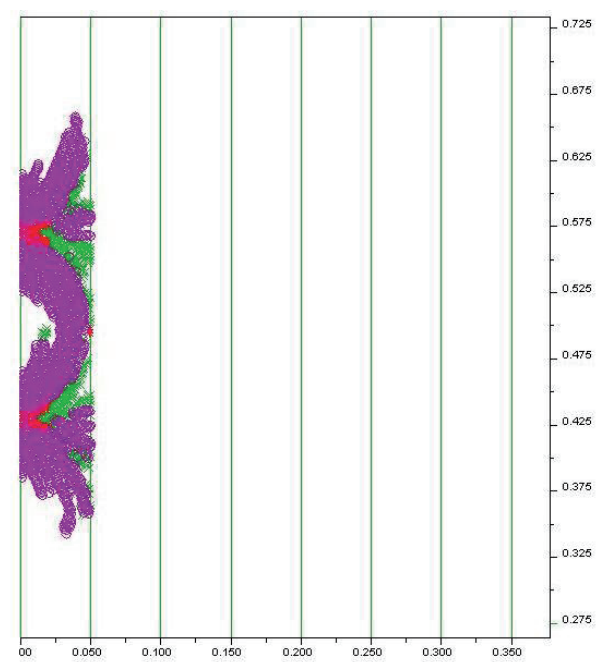

Fig. 9 Chipping formation in optimal cutter spacings joint spacing: $50 \mathrm{~mm}$ at step 1000 
Table 4 Effect of the cutter spacing on the TBM penetration for joint spacing equals $500 \mathrm{~mm}$

\begin{tabular}{|c|c|c|c|c|c|c|}
\hline $\begin{array}{l}\text { CSp } \\
(\mathrm{mm})\end{array}$ & $\begin{array}{l}\mathrm{CS} \\
(\mathrm{MPa})\end{array}$ & $\begin{array}{l}\text { CT } \\
(\mathrm{mm})\end{array}$ & $\begin{array}{l}\mathrm{CA} \\
\left(\mathrm{cm}^{2}\right)\end{array}$ & $\begin{array}{l}\mathrm{CW} / \mathrm{CT} \\
-\end{array}$ & $\begin{array}{l}\mathrm{CA} / \mathrm{CS} \\
\left(\mathrm{cm}^{2} / \mathrm{MPa}\right)\end{array}$ & $\mathrm{P}_{\mathrm{cs}} / \mathrm{P}_{60}$ \\
\hline 60 & 196.1 & 18.1 & 16.9 & 3.315 & 0.08618 & 1.00 \\
\hline 70 & 217.0 & 19.7 & 17.6 & 3.553 & 0.08111 & 0.94 \\
\hline 80 & 226.4 & 21.3 & 18.1 & 3.756 & 0.07995 & 0.93 \\
\hline 90 & 256.0 & 22.9 & 21.7 & 3.930 & 0.08477 & 0.98 \\
\hline 100 & 269.9 & 25.1 & 24.5 & 3.984 & 0.09077 & 1.05 \\
\hline 110 & 288.1 & 26.4 & 28.8 & 4.167 & 0.09997 & 1.16 \\
\hline 120 & 295.5 & 25.2 & 26.4 & 4.762 & 0.08934 & 1.04 \\
\hline 130 & 304.7 & 23.1 & 27.9 & 5.628 & 0.09157 & 1.06 \\
\hline 140 & 311.8 & 22.5 & 28.6 & 6.222 & 0.09173 & 1.06 \\
\hline 150 & $\mathrm{NC}$ & $\mathrm{NC}$ & $\mathrm{NC}$ & $\mathrm{NC}$ & $\mathrm{NC}$ & $\mathrm{NC}$ \\
\hline
\end{tabular}

Table 5 Effect of the cutter spacing on the TBM penetration for joint spacing equals $400 \mathrm{~mm}$

\begin{tabular}{|c|c|c|c|c|c|c|}
\hline $\begin{array}{l}\text { CSp } \\
(\mathrm{mm})\end{array}$ & $\begin{array}{l}\mathrm{CS} \\
(\mathrm{MPa})\end{array}$ & $\begin{array}{l}\mathrm{CT} \\
(\mathrm{mm})\end{array}$ & $\begin{array}{l}\mathrm{CA} \\
\left(\mathrm{cm}^{2}\right)\end{array}$ & $\begin{array}{l}\mathrm{CW} / \mathrm{CT} \\
-\end{array}$ & $\begin{array}{l}\mathrm{CA} / \mathrm{CS} \\
\left(\mathrm{cm}^{2} / \mathrm{MPa}\right)\end{array}$ & $\mathrm{P}_{\mathrm{cs}} / \mathrm{P}_{60}$ \\
\hline 60 & 327.3 & 19.0 & 14.6 & 3.158 & 0.04461 & 1.00 \\
\hline 70 & 338.9 & 22.5 & 16.2 & 3.111 & 0.04780 & 1.07 \\
\hline 80 & 382.4 & 24.6 & 17.4 & 3.252 & 0.04550 & 1.02 \\
\hline 90 & 400.2 & 27.2 & 19.8 & 3.309 & 0.04948 & 1.11 \\
\hline 100 & 413.3 & 29.5 & 23.5 & 3.390 & 0.05686 & 1.27 \\
\hline 110 & 423.5 & 34.2 & 29.7 & 3.216 & 0.07013 & 1.57 \\
\hline 120 & 457.0 & 39.1 & 36.8 & 3.069 & 0.08053 & 1.81 \\
\hline 130 & 478.0 & 24.5 & 32.0 & 5.306 & 0.06695 & 1.50 \\
\hline 140 & 485.1 & 21.9 & 27.5 & 6.393 & 0.05669 & 1.27 \\
\hline 150 & 497.4 & 20.2 & 25.6 & 7.426 & 0.05147 & 1.15 \\
\hline
\end{tabular}

Table 6 Effect of the cutter spacing on the TBM penetration for joint spacing equals $300 \mathrm{~mm}$

\begin{tabular}{ccccccc}
\hline $\begin{array}{c}\mathrm{CSp} \\
(\mathrm{mm})\end{array}$ & $\begin{array}{c}\mathrm{CS} \\
(\mathrm{MPa})\end{array}$ & $\begin{array}{c}\mathrm{CT} \\
(\mathrm{mm})\end{array}$ & $\begin{array}{c}\mathrm{CA} \\
\left(\mathrm{cm}^{2}\right)\end{array}$ & $\begin{array}{c}\mathrm{CW} / \mathrm{CT} \\
-\end{array}$ & $\begin{array}{c}\mathrm{CA} / \mathrm{CS} \\
\left(\mathrm{cm}^{2} / \mathrm{MPa}\right)\end{array}$ & $\begin{array}{c}\mathrm{P}_{\mathrm{cs}} / \mathrm{P}_{60} \\
-\end{array}$ \\
\hline 60 & 294.1 & 18.4 & 19.5 & 3.261 & 0.06630 & 1.00 \\
70 & 302.3 & 19.5 & 21.0 & 3.590 & 0.06947 & 1.05 \\
80 & 321.7 & 21.0 & 21.9 & 3.810 & 0.06808 & 1.03 \\
90 & 359.2 & 22.9 & 23.1 & 3.930 & 0.06431 & 0.97 \\
100 & 372.0 & 24.2 & 25.2 & 4.132 & 0.06774 & 1.02 \\
110 & 379.1 & 26.5 & 28.6 & 4.151 & 0.07544 & 1.14 \\
120 & 384.5 & 29.7 & 31.2 & 4.040 & 0.08114 & 1.22 \\
130 & 392.0 & 25.4 & 26.3 & 5.118 & 0.06709 & 1.01 \\
140 & 402.9 & 23.5 & 24.1 & 5.957 & 0.05982 & 0.90 \\
150 & 409.1 & 21.5 & 23.2 & 6.977 & 0.05671 & 0.86 \\
\hline
\end{tabular}

Table 7 Effect of the cutter spacing on the TBM penetration for joint spacing equals $200 \mathrm{~mm}$

\begin{tabular}{|c|c|c|c|c|c|c|}
\hline $\begin{array}{l}\text { CSp } \\
(\mathrm{mm})\end{array}$ & $\begin{array}{l}\mathrm{CS} \\
(\mathrm{MPa})\end{array}$ & $\begin{array}{l}\text { CT } \\
(\mathrm{mm})\end{array}$ & $\begin{array}{l}\mathrm{CA} \\
\left(\mathrm{cm}^{2}\right)\end{array}$ & $\begin{array}{l}\mathrm{CW} / \mathrm{CT} \\
-\end{array}$ & $\begin{array}{l}\mathrm{CA} / \mathrm{CS} \\
\left(\mathrm{cm}^{2} / \mathrm{MPa}\right)\end{array}$ & $\mathrm{P}_{\mathrm{cs}} / \mathrm{P}_{60}$ \\
\hline 60 & 477.5 & 13.4 & 14.2 & 4.478 & 0.02974 & 1.00 \\
\hline 70 & 484.9 & 15.1 & 17.5 & 4.636 & 0.03609 & 1.21 \\
\hline 80 & 495.6 & 16.8 & 19.8 & 4.762 & 0.03995 & 1.34 \\
\hline 90 & 527.9 & 21.5 & 23.2 & 4.186 & 0.04395 & 1.48 \\
\hline 100 & 537.6 & 22.8 & 26.4 & 4.386 & 0.04911 & 1.65 \\
\hline 110 & 545.0 & 23.1 & 29.2 & 4.762 & 0.05358 & 1.80 \\
\hline 120 & 569.1 & 27.2 & 33.1 & 4.412 & 0.05816 & 1.96 \\
\hline 130 & 573.9 & 28.3 & 34.9 & 4.594 & 0.06081 & 2.04 \\
\hline 140 & 577.5 & 18.5 & 28.0 & 7.568 & 0.04848 & 1.63 \\
\hline 150 & 582.4 & 17.2 & 26.2 & 8.721 & 0.04499 & 1.51 \\
\hline
\end{tabular}

Table 8 Effect of the cutter spacing on the TBM penetration for joint spacing equals $100 \mathrm{~mm}$

\begin{tabular}{ccccccc}
\hline $\begin{array}{c}\mathrm{CSp} \\
(\mathrm{mm})\end{array}$ & $\begin{array}{c}\mathrm{CS} \\
(\mathrm{MPa})\end{array}$ & $\begin{array}{c}\mathrm{CT} \\
(\mathrm{mm})\end{array}$ & $\begin{array}{c}\mathrm{CA} \\
\left(\mathrm{cm}^{2}\right)\end{array}$ & $\begin{array}{c}\mathrm{CW} / \mathrm{CT} \\
-\end{array}$ & $\begin{array}{c}\mathrm{CA} / \mathrm{CS} \\
\left(\mathrm{cm}^{2} / \mathrm{MPa}\right)\end{array}$ & $\begin{array}{c}\mathrm{P}_{\mathrm{cs}} / \mathrm{P}_{60} \\
-\end{array}$ \\
\hline 60 & 517.2 & 21 & 13.3 & 2.857 & 0.02572 & 1.00 \\
70 & 556.0 & 22.1 & 17.2 & 3.167 & 0.03094 & 1.20 \\
80 & 572.6 & 24.8 & 19.9 & 3.226 & 0.03475 & 1.35 \\
90 & 642.1 & 27.5 & 23.8 & 3.273 & 0.03707 & 1.44 \\
100 & 667.0 & 29.0 & 28.5 & 3.448 & 0.04273 & 1.66 \\
110 & 682.9 & 34.7 & 32.6 & 3.170 & 0.04774 & 1.86 \\
120 & 697.3 & 40.4 & 41.3 & 2.970 & 0.05923 & 2.30 \\
130 & 716.6 & 48.1 & 54.4 & 2.703 & 0.07591 & 2.95 \\
140 & 729.2 & 52.5 & 58.9 & 2.667 & 0.08077 & 3.14 \\
150 & 742.1 & 42.4 & 51.1 & 3.538 & 0.06886 & 2.68 \\
\hline
\end{tabular}

Table 9 Effect of the cutter spacing on the TBM penetration for joint spacing equals $50 \mathrm{~mm}$

\begin{tabular}{ccccccc}
\hline $\begin{array}{c}\mathrm{CSp} \\
(\mathrm{mm})\end{array}$ & $\begin{array}{c}\mathrm{CS} \\
(\mathrm{MPa})\end{array}$ & $\begin{array}{c}\mathrm{CT} \\
(\mathrm{mm})\end{array}$ & $\begin{array}{c}\mathrm{CA} \\
\left(\mathrm{cm}^{2}\right)\end{array}$ & $\begin{array}{c}\mathrm{CW} / \mathrm{CT} \\
-\end{array}$ & $\begin{array}{c}\mathrm{CA} / \mathrm{CS} \\
\left(\mathrm{cm}^{2} / \mathrm{MPa}\right)\end{array}$ & $\begin{array}{c}\mathrm{P}_{\mathrm{cs}} / \mathrm{P}_{60} \\
-\end{array}$ \\
\hline 60 & 613.9 & 22.2 & 18.7 & 2.703 & 0.03046 & 1.00 \\
70 & 624.7 & 23.9 & 20.3 & 2.929 & 0.03250 & 1.07 \\
80 & 639.1 & 25.1 & 22.5 & 3.187 & 0.03521 & 1.16 \\
90 & 682.0 & 27.4 & 25.1 & 3.285 & 0.03680 & 1.21 \\
100 & 691.5 & 31.2 & 28.5 & 3.205 & 0.04121 & 1.35 \\
110 & 712.0 & 33.4 & 30.6 & 3.293 & 0.04298 & 1.41 \\
120 & 731.0 & 37.5 & 34.1 & 3.200 & 0.04665 & 1.53 \\
130 & 769.1 & 41.2 & 42.8 & 3.155 & 0.05565 & 1.83 \\
140 & 792.5 & 47.8 & 55.6 & 2.929 & 0.07016 & 2.30 \\
150 & 821.3 & 44.2 & 54.8 & 3.394 & 0.06879 & 2.26 \\
\hline
\end{tabular}


In these tables, it is worth noting that the chip shape refers to the ratio of the chip width to chip thickness in the fifth column. The lower the ratio, the shape is closer to cubic and the efficiency of the TBM is higher. On the contrary, the higher the ratio, the more frequently the chipping occurs in the tunneling process and the vibration of the cutterhead is low. The ratio of the chipping area to the chipping stress denotes the yield of rock chips per unit cutter force. It indirectly represents the TBM penetration [10]. The last columns shows the ratio of Pcs to P60, where Pcs denotes the penetration rate with the cutter spacing and P60 represents the penetration rate with the cutter spacing of $60 \mathrm{~mm}$.

As can be seen from the above tables, an optimal state of cutter spacing exists for each class of joint spacing. The relationship between the cutter spacing and the chip thickness, and the chipping area for each class of joint spacing are shown in Figs. 10-15.

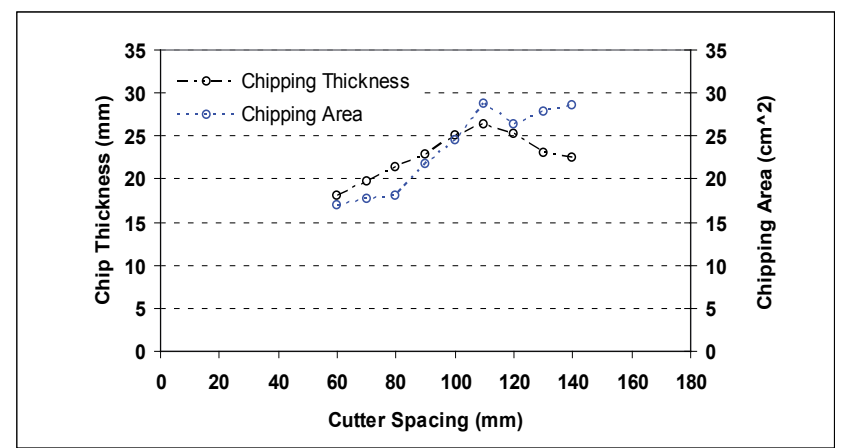

Fig. 10 Variation of chip thickness and chipping area with the different cutter spacing for joint spacing: $500 \mathrm{~mm}$

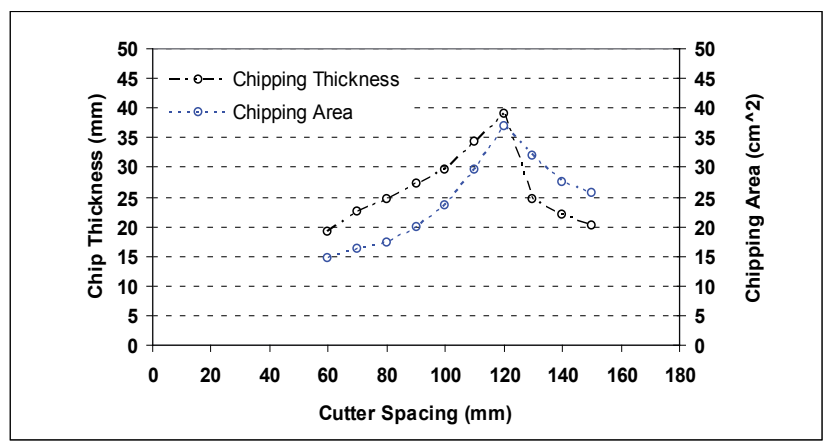

Fig. 11 Variation of chip thickness and chipping area with the different cutter spacing for joint spacing: $400 \mathrm{~mm}$

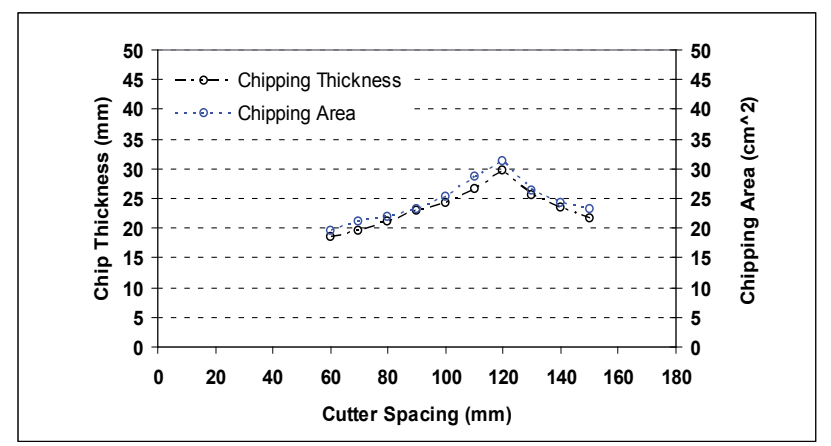

Fig. 12 Variation of chip thickness and chipping area with the different cutter spacing for joint spacing: $300 \mathrm{~mm}$

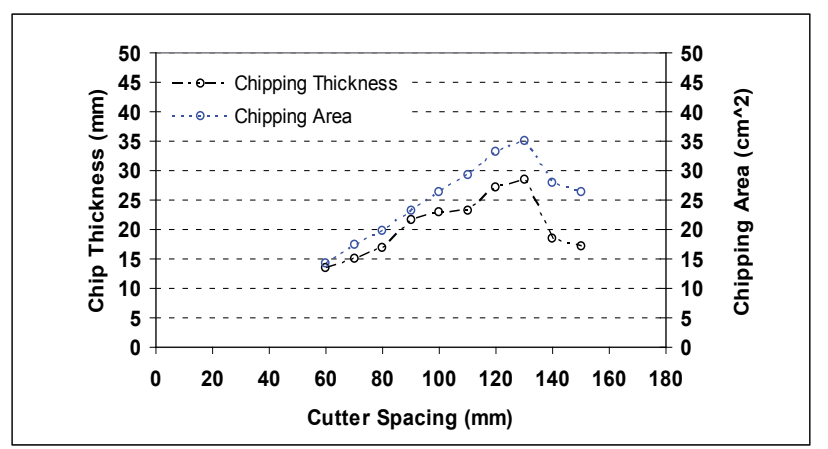

Fig. 13 Variation of chip thickness and chipping area with the different cutter spacing for joint spacing: $200 \mathrm{~mm}$

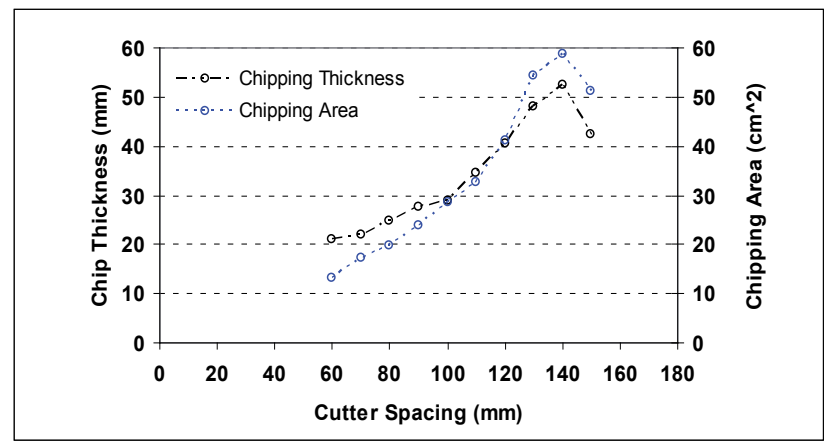

Fig. 14 Variation of chip thickness and chipping area with the different cutter spacing for joint spacing: $100 \mathrm{~mm}$

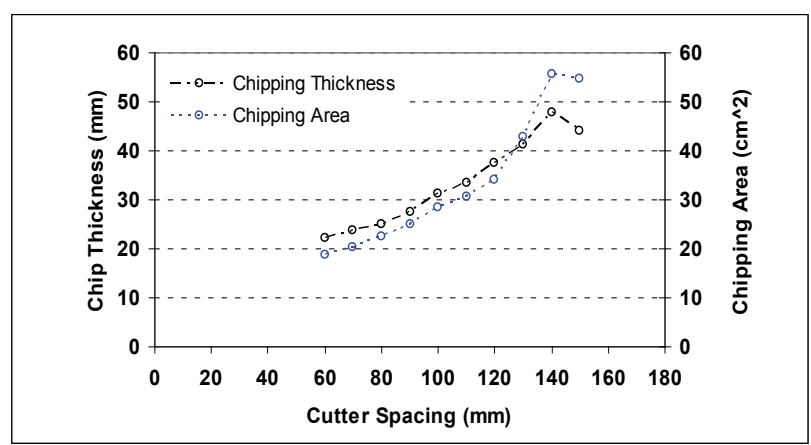

Fig. 15 Variation of chip thickness and chipping area with the different cutter spacing for joint spacing: $50 \mathrm{~mm}$

When the cutter spacing is less than the optimum, in all of classes, any increase in cutter spacing will result in an increase in the chip thickness and the chipping area. However, these parameters decrease when the cutter spacing is more than the obtained optimum amount. The relationship of the ratio of chip width to chip thickness, Pcs/P60 and cutter stress with cutter spacing are shown in Figs. 16-21. 


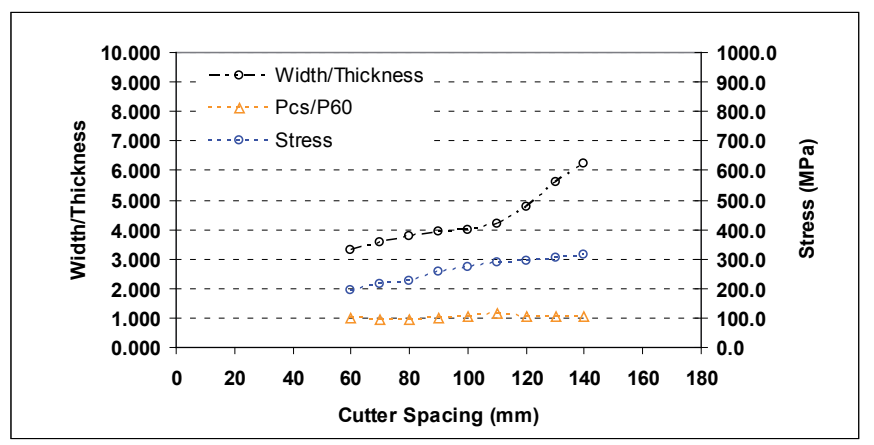

Fig. 16 The relationship between the ratio of chip width to chip thickness, $\mathrm{P}_{\mathrm{cs}} / \mathrm{P}_{60}$ and cutter stress with different cutter spacing for joint spacing: $500 \mathrm{~mm}$

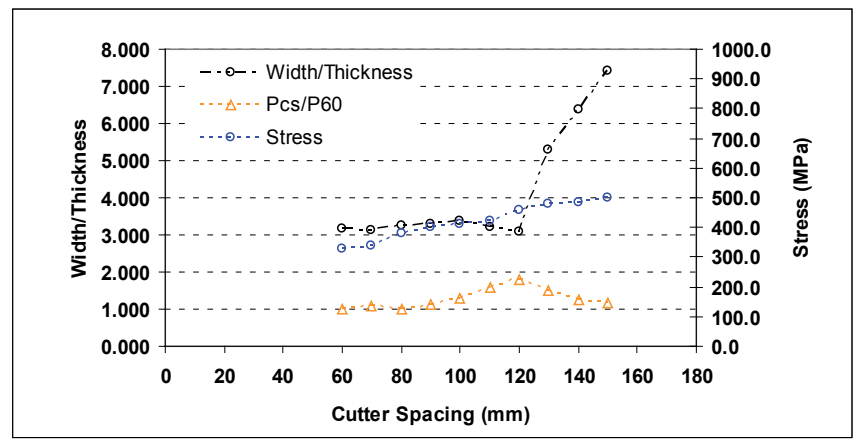

Fig. 17 The relationship between the ratio of chip width to chip thickness, $\mathrm{P}_{\mathrm{cs}} / \mathrm{P}_{60}$ and cutter stress with different cutter spacing for joint spacing: $400 \mathrm{~mm}$

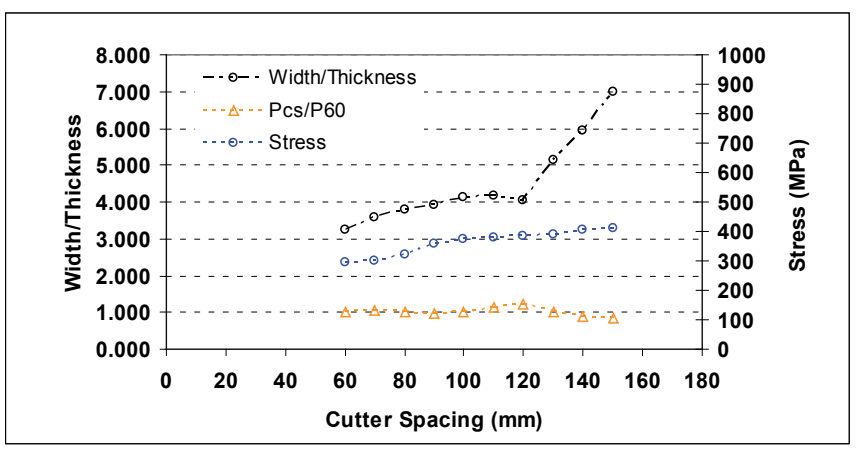

Fig. 18 The relationship between the ratio of chip width to chip thickness, $\mathrm{P}_{c \mathrm{~s}} / \mathrm{P}_{60}$ and cutter stress with different cutter spacing for joint spacing: $300 \mathrm{~mm}$

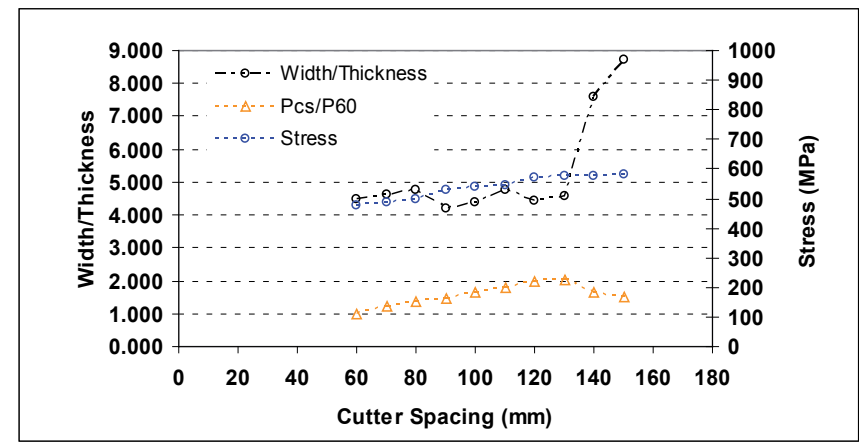

Fig. 19 The relationship between the ratio of chip width to chip thickness, $\mathrm{P}_{c \mathrm{~s}} / \mathrm{P}_{60}$ and cutter stress with different cutter spacing for joint spacing: $200 \mathrm{~mm}$

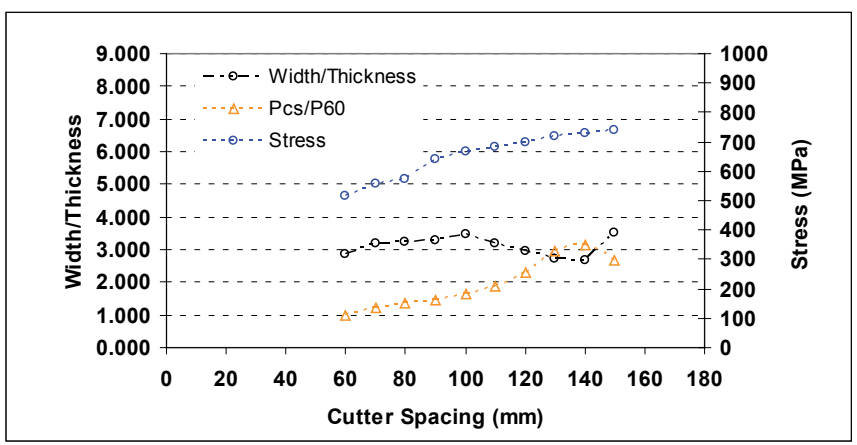

Fig. 20 The relationship between the ratio of chip width to chip thickness, $\mathrm{P}_{c s} / \mathrm{P}_{60}$ and cutter stress with different cutter spacing for joint spacing: $100 \mathrm{~mm}$

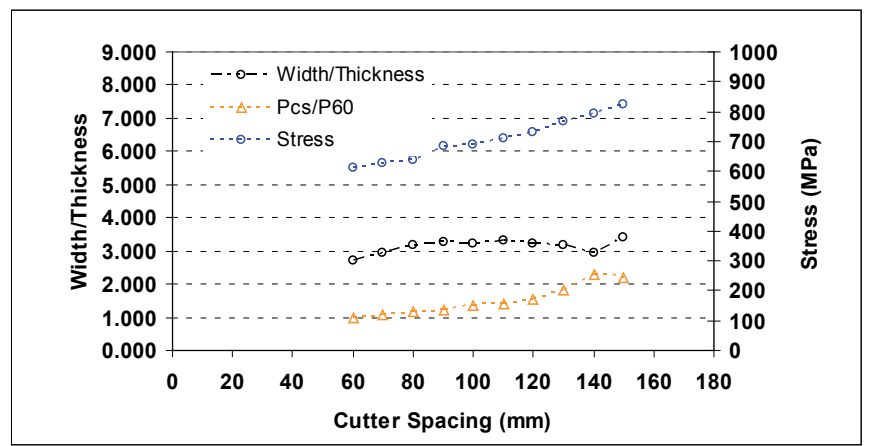

Fig. 21 The relationship between the ratio of chip width to chip thickness, $\mathrm{P}_{c s} / \mathrm{P}_{60}$ and cutter stress with different cutter spacing for joint spacing: $50 \mathrm{~mm}$

As can be seen, the critical cutter stress required to chip the rock increases with increasing cutter spacing in all of the joints spacing classes. The ratio of chip width to chip thickness is generally varies with the changes in the cutter spacing. The ratio of Pcs to P60 is one of the main considered criteria for selecting the optimal cutter spacing in each state of joint spacing. According to the experimental results conducted by Snowdon et al. $[4,5]$, the optimum value of the ratio of cutter spacing to penetration is about 10 to 15 and the optimum penetration is about $10 \mathrm{~mm}$ for some selected hard rocks. The numerically measured optimum cutter spacings in this study range from 110 to $140 \mathrm{~mm}$. Therefore, there is a good agreement between the current simulation results and former experimental measurements, while the cutter shapes in the two studies are the same but the force differs.

The simulation results by Gong et al. [2] showed that there are two modes of rock crack initiation and propagation. One is that the crack initiates from the joint plane and propagates upward to the free surface when the joint spacing is in the lower range. The other is that the crack initiates from the crushed zone and propagates downwards to the joint plane when the joint spacing is in other upper range. Both of these cracking modes were observed in the cutter study.

As can be seen in the figures, for each state of joint spacing, a particular cutter spacing exists in which the optimization criteria such as chip thickness, chipping area, chip width/chip thickness and also significantly the defined penetration rate index (Pcs/P60) are maximum. The optimum cutter spacing for each joint spacing class can be seen in Fig. 22. 


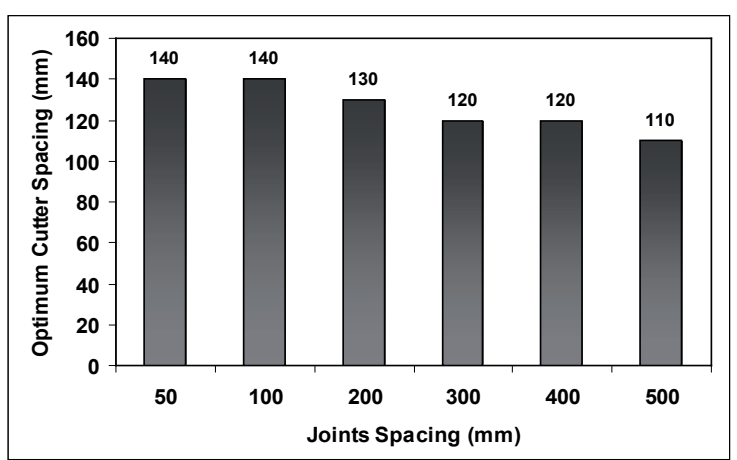

Fig. 22 The optimum cutter spacing for each joint spacing class

It is observed that with increasing the joint spacing in the model, the optimum cutter spacing will decrease. Achieving these optimum spacings for TBM disc cutters under different joint spacings, many of their design challenges in jointed rocks will be greatly improved, thus allowing such tunneling machines to operate with increased efficiency of lower energy and cost.

\section{Conclusions}

As drilling, mining and tunneling environments are becoming increasingly severe, advancements through drilling optimization are needed to hold down costs. Numerical models that can accurately simulate the tool-rock interaction and the failure mechanisms, including chip formation and interaction between adjacent indenters, could be used in parametric studies to determine optimal indenter designs, reducing much of the expensive and time-consuming experimental work which would otherwise have to be carried out to assess the performance of indenter designs. Most mechanical rock excavation techniques employ indentation as the means to induce rock fracture. The effects of cutter spacing in rock fragmentation induced by double cutters were numerically examined by UDEC on a type of quartzite rocks found in the Ghomrood tunneling project area in Iran. In the developed model, different frequencies of the joints were considered to investigate the effect of jointing intensity on the optimum cutter spacing. It is pointed out that simultaneous loading with multiple cutters with an appropriate spacing seems to provide the possibility of forming larger rock chips and also to reach better penetration rate for each joints spacing. According to the simulated results, it is believed that the numerical simulation method will contribute to an improved knowledge of rock fragmentation in indentation, which will in turn help to enhance mining, drilling and tunneling efficiency through the improved design of mining tools and equipment, although it should be noted that all the computer programs have some limitations and some assumptions to simplify the problems, which to some extent reduce the accuracy.

\section{References}

[1] Nelson, P. P., Ingraffea, A. R., O’Rourke, T. D. "TBM performance prediction using fracture parameters." International Journal of Rock Mechanics and Mining Sciences \& Geomechanics Abstracts. 22(3), pp. 189192. 1985. DOI: 10.1016/0148-9062(85)93234-6

[2] Gong, Q. M., Jiao, Y. Y., Zhao, J. "Numerical modelling of the effects of joint spacing on rock fragmentation by TBM cutters." Tunnelling and Underground Space Technology. 21(1), pp. 46-55. 2006. DOI: 10.1016/j.tust.2005.06.004

[3] Roxborough, F. F. "Fundamental studies on the mechanics of cutting rock with discs." In: Third Australian Tunneling Conference, Sydney, N. S. W. 1978. pp.43-47.

[4] Snowdon, R. A., Temporal, J., Hignett, H. J. "A linear rock cutting rig." Supplementary report 588. Tunnels and Underground Pipes Division, Structures Department, Transport and Road Research Laboratory, Crowthorne, Berkshire, 1981.

[5] Snowdon, R. A., Ryley, M. D., Temporal, J. "A study of disc cutting in selected British rocks." International Journal of Rock Mechanics and Mining Sciences \& Geomechanics Abstracts. 19(3), pp. 107-121. 1982. DOI: 10.1016/0148-9062(82)91151-2

[6] Cook, N. G. W., Hood, M., Tsai, F. "Observations of Crack Growth in Hard Rock Loaded by an Indenter." International Journal of Rock Mechanics and Mining Sciences \& Geomechanics Abstracts. 21(2), pp. $97-$ 107. 1984. DOI: 10.1016/0148-9062(84)91177-X

[7] Rostami, J., Ozdemir, L. "A new model for performance prediction of hard rock TBMs." In: 1993 Rapid Excavation and Tunneling Conference, [1993 RETC], Boston, Massachusetts, June 13-17, 1993. pp. 793-809.

[8] Liu, H. Y., Kou, S. Q., Lindqvist, C. A., Tang, C. A. "Numerical simulation of the rock fragmentation process induced by indenters." International Journal of Rock Mechanics and Mining Sciences. 39(4), pp. 491-505. 2002. DOI: 10.1016/S1365-1609(02)00043-6

[9] Gong, Q. M., Zhao, J., Jiao, Y. Y. "Numerical modeling of the effects of joint orientation on rock fragmentation by TBM cutters." Tunnelling and Underground Space Technology. 20(2), pp. 183-191. 2005.

DOI: $10.1016 /$ j.tust.2004.08.006

[10] Gong, Q. M., Zhao, J., Hefny, A. M. "Numerical simulation of rock fragmentation process induced by two TBM cutters and cutter spacing optimization." Tunnelling and Underground Space Technology. 21(3-4), pp. 263. 2006. DOI: 10.1016/j.tust.2005.12.124

[11] Gertsch, R., Gertsch, L., Rostami, J. "Disc cutting tests in Colorado Red Granite: Implications for TBM performance prediction." International Journal of Rock Mechanics and Mining Sciences. 44(2), pp. 238-246. 2007. DOI: 10.1016/j.ijrmms.2006.07.007

[12] Marji, M. F., Nasab, H. H., Morsedi, A. H. "Numerical Modeling of Crack Propagation in Rocks under TBM Disc Cutters." Journal of Mechanics of Materials and Structures. 4(3), pp. 605-627. 2009. DOI: 10.2140/jomms.2009.4.605

[13] Cho, J.-W., Jeon, S., Yu, S.-H., Chang, S.-H. "Optimum spacing of TBM disc cutters: a numerical simulation using the three-dimensional dynamic fracturing method." Tunnelling and Underground Space Technology. 25(3), pp. 230-244. 2010. DOI: 10.1016/j.tust.2009.11.007

[14] Moon, T., Oh, J. "A Study of Optimal Rock-Cutting Conditions for Hard Rock TBM Using the Discrete Element Method." Rock Mechanics and Rock Engineering. 45(5), pp. 837-849. 2012. DOI: $10.1007 / \mathrm{s} 00603-011-0180-3$

[15] Huo, J., Sun, W., Su, P., Deng, L. "Optimal Disc Cutters Plane Layout Design of the Full-Face Rock Tunnel Boring Machine (TBM) Using an Ant Colony Optimization Algorithm." In: Proceedings of the 2nd International Conference on Intelligent Robotics and Applications ICIRA '09. pp. 443-452. 2009. DOI: 10.1007/978-3-642-10817-4_44 
[16] Sun, W., Huo, J., Chen, J., Li, Z., Zhang, X., Guo, L., Zhao, H., Zhao, Y. "Disc cutters' layout design of the full-face rock tunnel boring machine (TBM) using a cooperative co-evolutionary algorithm." Journal of Mechanical Science and Technology. 25(2), pp. 415-427. 2011. DOI: $10.1007 / \mathrm{s} 12206-010-1225-3$

[17] Xia, Y., Ouyang, T., Zhang, X., Luo, D. "Mechanical model of breaking rock and force characteristic of disc cutter." Journal of Central South University. 19(7), pp. 1846-1852. 2012.

DOI: $10.1007 / \mathrm{s} 11771-012-1218-8$

[18] Wang, Z., Wang, W. S., Wang, J., Liu, C. "Predicting and verifying forces by using different cutters and spaces." In: Practical Applications of Intelligent Systems, Advances in Intelligent Systems and Computing. 279, Springer-Verlag, Berlin, Heidelberg, pp. 177-186. 2014.

DOI: 10.1007/978-3-642-54927-4_17

[19] Lu, F., Zhang, C., Sun, J., Tian, J. X., Liu, M., Wu, Y. H. "Study on Rockbreaking Simulation and Experiment of Double Disc Cutter of TBM." International Journal of Engineering Research in Africa. 23, pp. 80-88. 2016. DOI: 10.4028/www.scientific.net/JERA.23.80
[20] Cundall, P. A. "A computer model for simulating progressive large scale movements in blocky rock systems." In: Proceedings of the international symposium on rock fracture, Nancy, France, October 1971. International Society for Rock Mechanics (ISRM), 1, paper no. 11-8, pp 129-136. 1971.

[21] Itasca Consulting Group. "UDEC reference manual." Version 4.0, Minneapolis, Minnesota, USA (2004).

[22] Farrokh, E. "Prediction of ground convergence in Ghomroud tunnel and study of convergence effect on the TBM performance." M.Sc. thesis, Department of Mining Engineering, Tehran University, Iran, 2004. (in Persian with English abstract)

[23] Bruland, A. "Hard rock tunnel boring." Doctoral Thesis, Norwegian University of Science and Technology, Trondheim. 1998. 